\title{
Overview of the Forensic Photography
}

\author{
*Alain Wittmann \\ Forensic photographer, South America
}

Submission: January 30, 2017; Published: March 03, 2017

*Corresponding author: Alain Wittmann, Forensic photographer, self-employed, Alguaciles 117, Surco, Lima, Peru, Tel: 00519999 90890; Email: fotosalain@gmail.com

\begin{abstract}
Forensic photography is a specialty and has always played an important part in forensic investigation. Photographs are taken to produce a permanent record mainly intended to preserve any evidence found from destruction.
\end{abstract}

\section{Introduction}

Usually when talking about forensic photographers, reference is made to a person who produces a permanent visual record of accidents or crime scenes, but forensic photography also plays an important role all forensic activities including exhumation (Figure 1), autopsies, medical examinations, artifacts, clothing, etc. Forensic photography is characterized by and requires scientific knowledge and techniques to discover and preserve information and details found during the investigation. The main objective is to record and graphically document evidence for legal purposes because it is an element of legal proof. Before taking a photograph, the photographer must analyze the scene and the elements needed in the shooting (e.g.: appropriate ISO, aperture, speed angle of view to avoid potential distortions of distance, lighting conditions, lens, etc.) in order to obtain the correct results. Each photo must have a photo evidence scales and case number (Figure 2) when is possible, evidence number, arrow (Figure 3), north indicator, etc., must be placed according to photographic requirements and everything must be adapted to the size of the subject. All photos taken must be registered on a photographic record formin order to have a detailed record of all the photographs taken during the different stages of the investigation (e.g.: crime scene, exhumation, autopsy, etc.) [1]. Photographs must be taken in a series of sequential steps, such as general view, mid-range and detail. When possible and depending on the case, the photo evidence scale must be positioned in order to orient the picture (Figure 4) (e.g.: for an autopsy or medical examination the scale should be oriented towards the skull as much as possible) [2]. Depending on the needs of the case, different types of photography are used, such as color, black and white, ultraviolet, and infrared in order to show various aspects of an object, substance or other evidence. It is imperative for the forensic photographer to follow a legal photography protocol and ensure that the photographic evidence constitutes a fair and accurate representation that will be admissible in a court of law. There are different protocols specific to each stage of the forensic photography (e.g.: exhumation, crime scene, autopsy, etc.) [3].
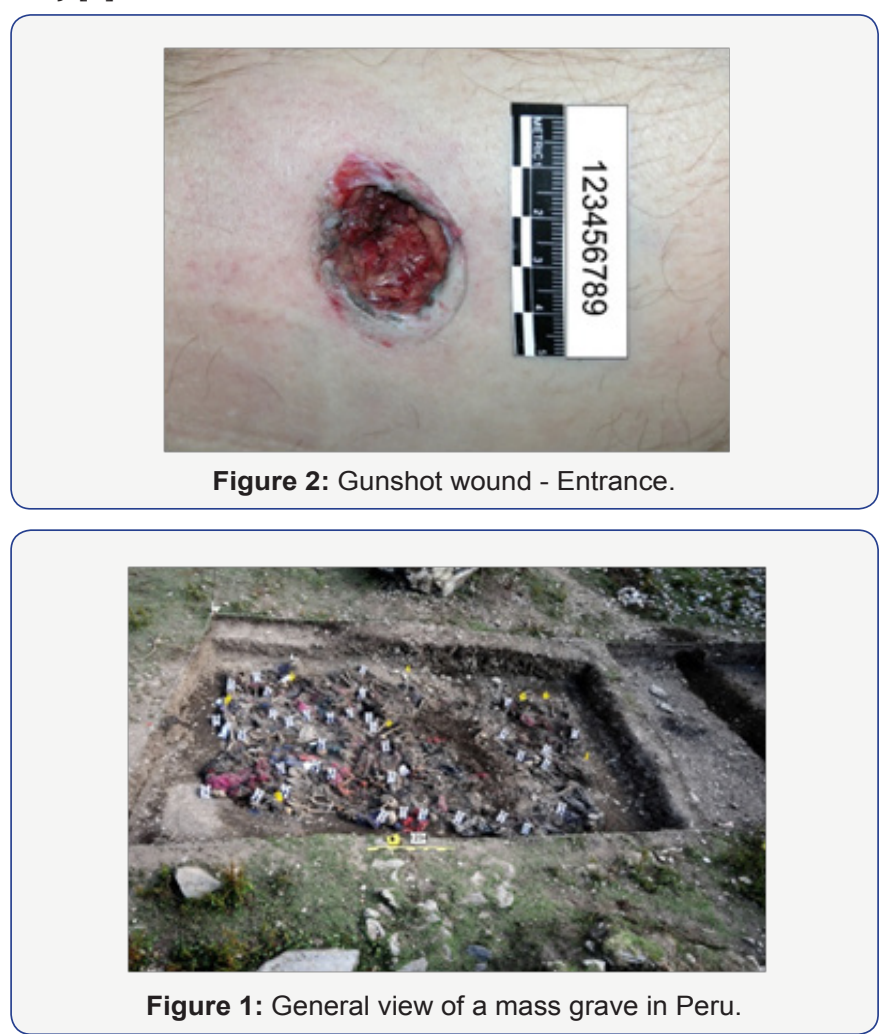


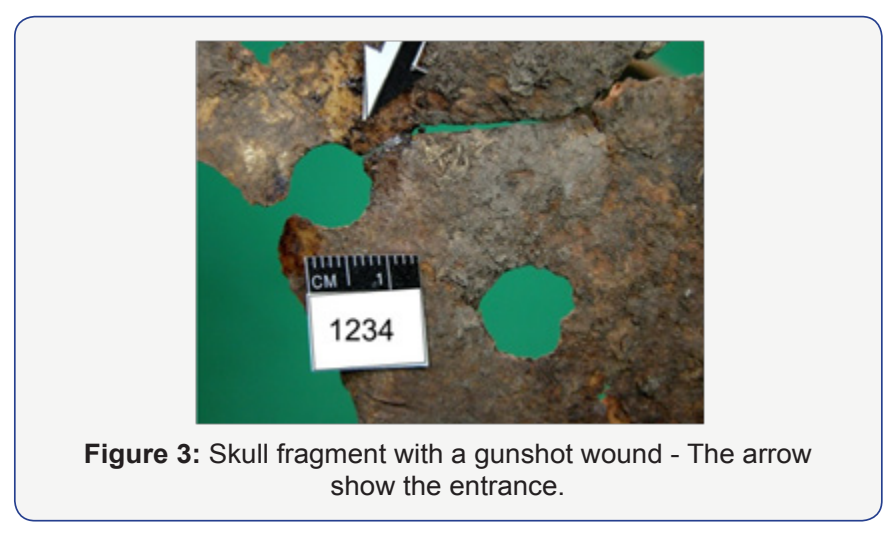

\section{Conclusion}

Forensic photography provides fair and accurate evidence that is used to document all reports during a forensic investigation and is an integral part of criminal investigation procedures and an element of legal proof. The photographer must be able to use the best photographic techniques in order to obtain the best results and must be well acquainted with police procedure as well as a good understanding of human anatomy.

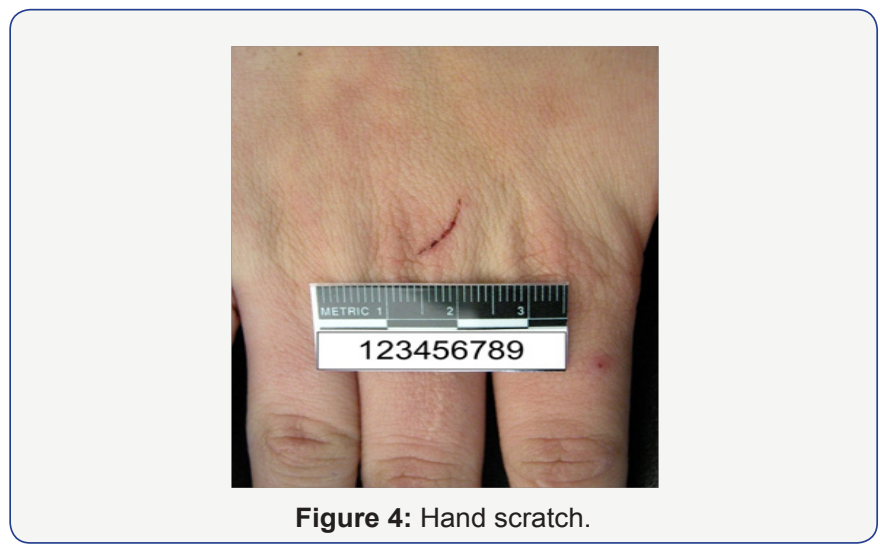

\section{References}

1. Alain Wittmann (2009) Recomendaciones básicas para una buena técnica de la fotografía forense en casos judiciales. IV Congreso Latino Americano de Antropología Forense, Perú.

2. Alain Wittmann (2014) Fotografía Forense aplicada a la antropóloga forense y bioarqueología. Perú p. 22,27,92,135.

3. Peruvian Forensic Anthropology Team (2012) Practical Manuel for the Forensic Investigation of Human Tight Violation. Forensic Photography, Peru, p. 36.

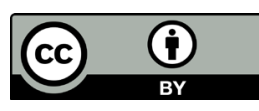

This work is licensed under Creative Commons Attribution 4.0 License DOI: $10.19080 /$ JFSCI.2017.02.555581 